\title{
Advantages of Integrating Technology Knowledge into Undergraduate Curriculum
}

\author{
Nicholas Nam \\ California Polytechnic University \\ San Luis Obispo, Ca
}

\begin{abstract}
Advancements in technology have made daily construction tasks easier and more efficient and will continue to do so. Cal Poly currently offers a BIM course but it is limited to certain programs and the extent of which these are taught are also limited. This paper will explore the inputs of current Cal Poly construction management students to see how there can be a successful implantation of technology courses and which programs to heavily integrate. The different types of programs available are increasing and are continuing to better themselves, and to have knowledge of these programs can help translate into skills that will be applicable in the workforce or for internships. Survey results have been analyzed with outcomes of all sorts, but in the end there is a consensus for the implementation of more technology within the construction management curriculum. The advantages this could give Cal Poly construction management undergraduate students over students from other colleges can be outlasting and can truly separate the $\mathrm{Cal}$ Poly student from the ordinary. The importance of technology is within the new generation of builders so it is imperative to give the students the resources they need in order to succeed in the construction world.
\end{abstract}

Key Words: BIM, Technology, Curriculum

\section{Introduction}

The world of construction has many different areas of work and every one of them is being affected by technology. Technology includes everything from the internet, to document control, to three dimensional modeling, to scheduling, to estimating, to site logistics, to cost controls, and many more things. Whether it's preconstruction, construction, or post construction, technology is helping the efficiency of all aspects of construction. Different generations have used different methods, but one thing that is common between every generation is that the efficiency of construction matters and anything that helps this efficiency of construction is considered beneficial.

Currently at Cal Poly San Luis Obispo, technology courses and technology knowledge is making its way into the curriculum in the form of a BIM class. The processes in which these classes are becoming relevant have been coming together at a slow pace (Sabongi 2008). This class has been optional and has now made its way to become a required course. There are many benefits to the current BIM class because it gives students the basic knowledge and introductions to some programs that are used in the industry today. It is taught by students and is relatable to internships for students. The capacities of BIM are to allow for the collaboration of others electronically to a construction project (Thomas and Miner, 2007) However, the current BIM class does not implement the technology to real life situations and can be limiting on how in depth certain programs are taught. There are many more ways to make this a better class and to implement certain programs in other ways than what used to be a technical elective class.

\section{Introduction of Technology in Industry}

Technology can be seen as how to do things electronically versus doing it physically. Currently there are many things technology has to offer. In general, BIM technology provides information supporting design, analysis, cost estimating, procurement, detailing construction simulation and much more (McCuen 2008). First let's explore document control. Programs like Procore offer a type of technology that keeps documents organized, and makes it easy to collaborate in the editing of these documents. In the construction industry, where there are documents being passed around such as subcontracts, submittals, RFIs, closeout documents, and much more, it is important to be able to keep track of all of these things. Another type of document control program is Bluebeam. Bluebeam has become a 
standard document reader but has expanded its potential to do much greater such as estimating and group editing. These are some of the programs that are dominant in document control and are drawing interest from students today.

BIM technology has evolved into three dimensional capabilities as well. Throughout industry today, there are uses of programs such as Revit, Tekla, and Archicad. These programs were asked about in the surveys sent to the students of Cal Poly, and there were mixed reviews on which they thought of with the most importance. The capabilities of these programs are all similar in which they allow you to model in 3D and more so take quantities off of these models. This has become prominent in industry because it greatly increases the time for quantity take offs. These take offs that were previously done by hand through drawings can now be done electronically through these programs. There are other programs that are specific for take offs and estimating such as the Revit plug-in Assemble and Vico. Different companies are testing different types of estimating tools and are investing in what they believe will pan out to be the most successful.

Finally a third type of technology that was looked at was the concept of clash detection. The usefulness of clash detection in buildings help subcontractors coordinate with each other so clashes are not made in the jobsite. To foreshadow these clashes in the preconstruction stage rather than meeting the clash physically in the job site saves a great amount of money. Programs that have been known for this that has been surveyed are BIM 360 Glue and Navisworks. Both of these programs have the capabilities to take in models from programs such as Archicad, Revit, and Tekla and are able to divide them up by subcontract trade, align accordingly, clash accordingly, and discuss solutions to possible problems caused by clashes.

\begin{tabular}{|c|c|c|c|}
\hline DIN Category & $\begin{array}{c}\text { Estimated Percent } \\
\text { of Reduction }\end{array}$ & Total Cost (\$ millions) & Average Cost Per Issue \\
\hline General Structures & $30.5 \%$ & 6.8 & $\$ 45,674$ \\
\hline Roadway/Drainage & $\mathbf{2 5 . 5} \%$ & 5.7 & 85,631 \\
\hline Wet Utilities/Drainage & $11.1 \%$ & 2.4 & 27,120 \\
\hline Bridges & $8.0 \%$ & 1.8 & 15,557 \\
\hline Noise Wall & $8.0 \%$ & 1.8 & 125,909 \\
\hline Retaining Wall & $7.7 \%$ & 1.7 & 21,818 \\
\hline Earthwork & $4.5 \%$ & 1.0 & 59,220 \\
\hline Electrical/ITS/FTMS & $2.6 \%$ & 0.6 & 15,557 \\
\hline Traffic & $2.1 \%$ & 0.5 & 18,174 \\
\hline Sign Structures & $0.1 \%$ & 0.02 & 738 \\
\hline
\end{tabular}

Figure 1. Estimated Cost Impact from the Use of 3D Modeling on the Mitchell Interchange Project (Parve 2007.)

In the figure above, there was a case study done by Lance Parve that showed the benefits of clash detection methods for the Mitchell Interchange project. This chart above shows the percentage of reduction of cost by category and the average cost it is per issue on an average project. Some categories were more affected than others, but the overall trend is that there is ways that $3 \mathrm{D}$ modeling and clash detection can help save money in the long term of a project.

\section{Challenges of Technology in Industry}

There are many challenges in implementing all types of technology into the construction industry. One of the challenges may be the affordability to the programs for every person interested in technology. Licenses for many of these programs come at a large sum of money and it can be seem as not beneficial for projects of smaller sizes. More so than this, companies that do not work with large cost projects may not be able to afford some of the programs and functions of some of the technology that is offered. Profitability of these technology companies come with their trials, errors, and perfections of their technology so it cannot be undermined and given at very cheap costs. But economically it can be challenging for people who want to obtain these technologies for their benefits. 
Another challenge that is faced with implanting technology into the industry is the education of the technology. The focus of this paper is the implementation but also the integration of the education of the technology available to help increase efficiency in the construction world. To teach the entry level position workers, otherwise seen as greatly the college graduates and interns, is imperative to using the technologies to its greatest capabilities. The acceptance of this technology by the older generation in the industry is also crucial in implanting the usefulness of these programs.

\section{Benefits of Technology in Industry}

The main benefit of knowing the skills to effectively use technology in the work force is efficiency. At the end of the day in the construction world, time is money, and saving time means that one will be saving money. Money can be saved in other ways such as lessening construction mistakes before they actually happen. There are many benefits that can happen in the just preconstruction stage of any building. 3D models that are used successfully used for the preconstruction stage allows benefits in visualization, resolving construction problems, space conflict analysis, and hazard analysis (Meadati 2009).

In the case of estimating, time can be saved by using technology versus doing hand estimates. If there are models of the building already accurately created from the architect, then it is absolutely more efficient to utilize technology to estimate. Not only is it going to save time in estimates with quantity, but it can be more accurate than a hand estimate. The programs capabilities can outdo the capabilities of people and additional functions are making these programs even more beneficial. If there is a way to be more accurate and save time in any construction process, it is definitely going to be beneficial.

Clash detection was talked about briefly, but this is another way that technology can be beneficial in the industry. One of the worst problems that can happen is to find a major cost problem on the jobsite during the time of construction. If these problems and clashes can be mitigated and coordinated with prior to even building it can save costs. It can save material costs as well as reconstruction cost and possibly even delay in schedule costs. The accuracy of these clash detection programs, allow for minute clashes to be found for repairs, maintenance, and renovation (Goedert and Meadati, 2008). Foreshadowing these issues before they actually appear can be the deciding factor whether a project is completed on time or behind schedule.

Not only does utilizing technology help cut down time and save costs onsite, but it can help the communication between all parties involved in a project. Document control technology helps the coordination of all documents between architect, contractor, and engineer be kept organized. Not only is it organized but it is also very easy to mock up and edit different documents which gives the other party instant feedback. The instant feedback through electronic documentation is more organized than paper copies and can be kept track of much more efficiently.

\section{Challenges of Effectively Implementing Technology into Curriculum}

There are many challenges within a school system to successfully educate students on how to properly use all the technology available. In the Cal Poly construction management curriculum there is a basic and required BIM course as well as a more advanced elective. The manners in which these are taught are by students in a way where the students are following the steps that the teacher is demonstrating. This is effective in a way where the basics of a program can be explored but in a sense it is just copying what the teacher is doing. A better way to implement this is to teach the basics then let the students explore on their own to be familiar with the program itself.

The challenge that is presented is how to implement these programs to daily assignments or group assignments that will get the students minds stimulated to use their construction knowledge and use the technology as an asset of that knowledge. The first step in this is to get the professors familiar with the technology first so that they can be helpful in assisting technical issues the students will face. In the survey and study done below, there will be different ways explored in how there can be a successful integration among the students and teachers with technology in either technical elective courses or the main construction management labs. 


\section{Methodology}

The process of getting results in the study was to take the input of other colleagues to see what their take on the issue of technology related to construction and the Cal Poly curriculum was.

The survey consisted of ten questions and was sent out to construction management majors and minors.

Construction management majors and minors was the demographic for the survey so it can be related to people who have worked for or will work for contractors. The reasoning behind why the whole school of Architecture wasn't involved was because there are many other programs that architects and architectural engineers use that were not going to be surveyed.

The survey questions were particular in which it offered students to express interest in things that they were interested in learning as well as technology they had already had experience with in the working industry. As well as these types of questions, they were asked how they would like to see technology courses and education implanted into the curriculum. More so than that, they also were asked about how they saw technology growing in the field of construction in the future. The results of this survey were the basis of the data used for the conclusions of this project.

\section{Results}

The first important question of this survey was which of these programs were already used during internships that the students have had. 


\section{Which of these programs have you used during an internship or job? (select all that apply)}



Figure 2. Which of these Programs have you used during an Internship or Job

Out of the 45 students surveyed 4 did not answer but the results were appropriate and scattered. Most of these options that the students had for this question are technology programs that are readily available in the Cal Poly construction management computer lab. Along with that, a lot of these programs are used within some of the labs. Seeing that all of the options were checked off by students who did the survey proves one thing. It proves that the internships that the students are having do deal with these technologies.

The next important question that was asked was which of these programs would the students want to learn more about. 


\section{Which of these programs do you want to learn more about in your construction management classes?}

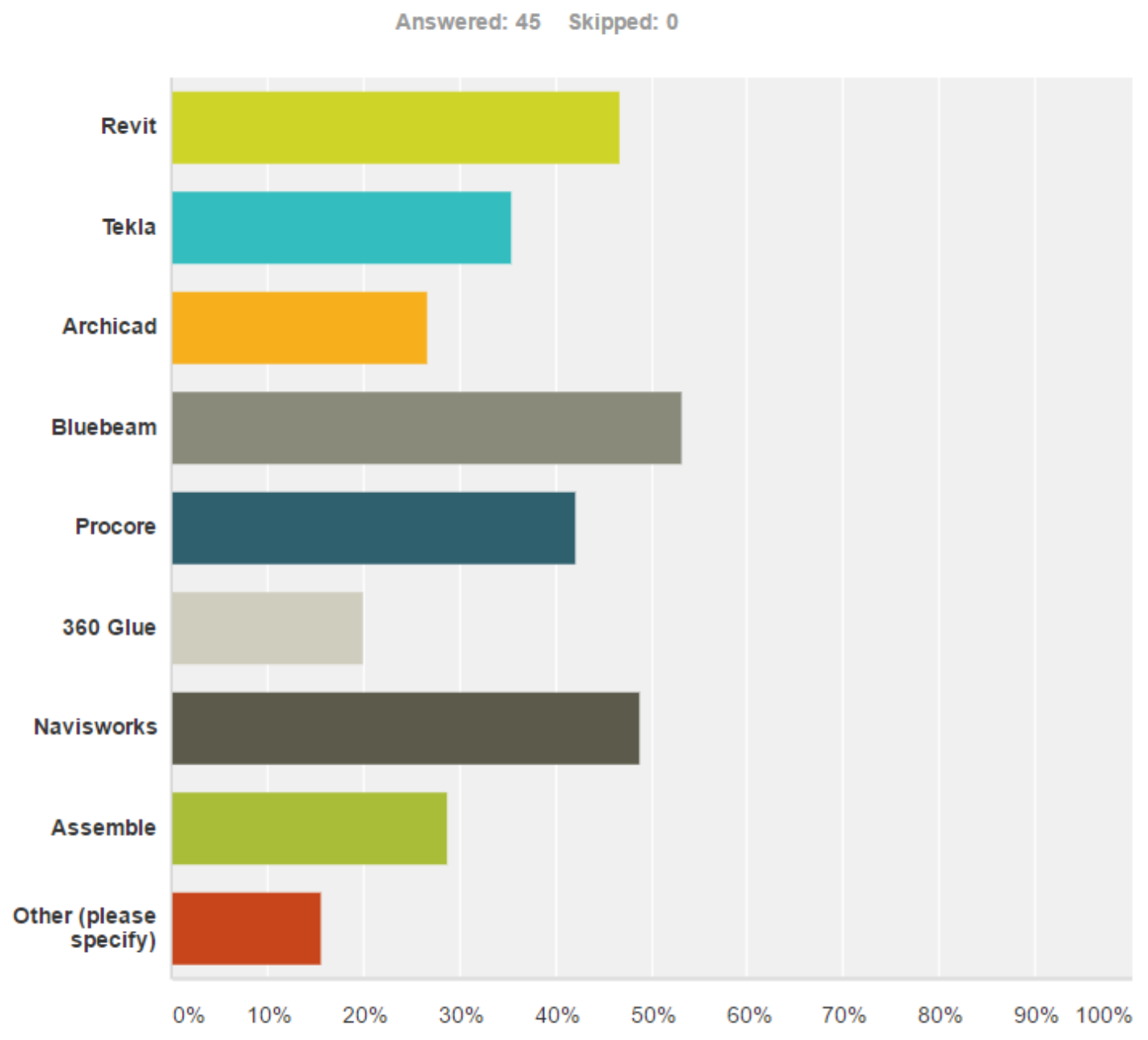

Figure 3. Which of these Programs do you want to learn more about in your Construction Classes?

These results were what were most surprising about the survey. The leading answer to this question was Bluebeam which is interesting because most students would say they were already proficient in Bluebeam and had to use them in previous internships. Knowing that that is a program that they want to know more about shows how there is a lack of Bluebeam education throughout the construction management BIM courses offered at Cal Poly.

Another thing to take from this survey question is the interest students had in Navisworks and Revit. Navisworks has many capabilities but is a program that industry is increasingly using for clash detection of BIM 360 glue. There is no real education to this program offered in the curriculum currently for BIM 360 glue is the prominent one being taught at Cal Poly. Along with Navisworks, there is interest in learning more about Revit. Revit is one of the most common 3D modeling programs and the lack of education in this is shocking. There should be more time spent using programs such as these because they are seen in industry more so than some of the programs that are being taught. 
A final question to the students that was interesting was how they would like to see the integration of these programs into the curriculum.

\section{Would you rather see a technology topics course, or would you like to see more programs be implemented into the construction management labs?}

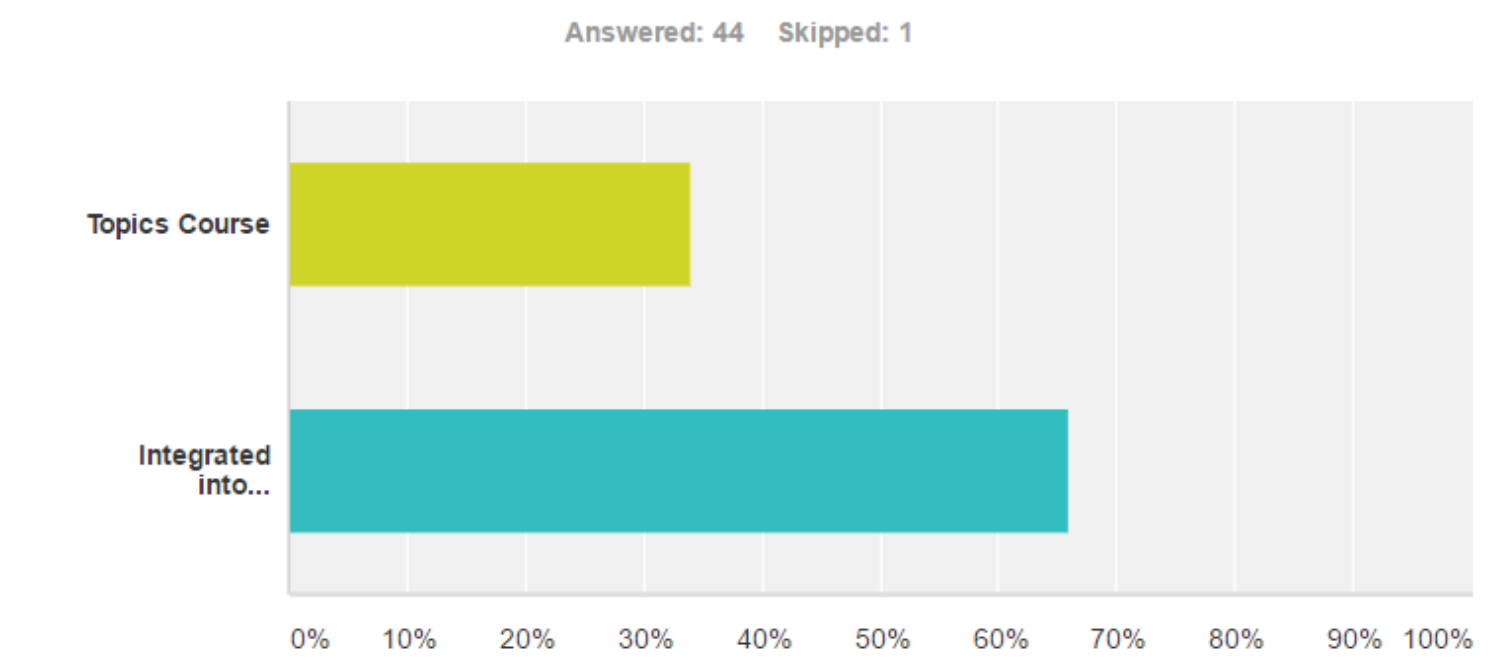

\begin{tabular}{l|ll}
\hline Answer Choices & Responses \\
\hline Topics Course & $\mathbf{3 4 . 0 9 \%}$ & 15 \\
\hline$\quad$ Integrated into construction management labs & $\mathbf{6 5 . 9 1 \%}$ & 29 \\
\hline Total & & 44 \\
\hline
\end{tabular}

Figure 4. Would you rather see a technology topics course, or would you like to see more programs be implemented into the construction management labs

From the results above it is seen that almost $66 \%$ of students would like to see these programs taught more intensively within their major labs than as technical electives. This is different than the approach Cal Poly currently has. The only major way to get involved with technology relating to construction is in topic courses. It can be seen that the students want it to be implemented in actual lab classes because it can be more applicable to them in relation to the major labs.

\section{Conclusion}

From the research of how important technology is and will become in the industry of construction, it is important to see that it will just continue to grow. The benefits of the technology offered to students and workers are something that needs to be educated about thoroughly. In conclusion, this education should be integrated within the main construction management labs offered at Cal Poly. In doing this, it is important that the professors learn these programs so they can help educate and guide students who need help. It will be important to integrate technology within the labs because it will be more applicable to the students when entering the construction industry. To be able 
to relate different types of construction and utilize technology will produce the best outcome of technology knowledge to the students at Cal Poly.

From the results of the survey, it was concluded that there is a thirst for more knowledge on technology altogether and some programs more than others. Relating this to what is already seen in the construction industry, it is important to educate students on the technology so they may use this knowledge out in the construction industry.

\section{References}

Goedert, J.D. \& Meadati, P. (2008). Integration of construction process documentation into Building Information Modeling, Journal of Construction Engineering and Management

Parve, L. (2007). 3D Engineered Models for Construction. Understanding the Benefits of 3D Modeling in Construction: The Wisconsin Case Study https://www.fhwa.dot.gov/construction/pubs/hif13050.pdf

Meadati, P. (2009) BIM Extension into Later Stages of Project Life Cycle

McCuen, T. L. (2008) Building Information Modeling and the Interactive Capability Maturity Model

Sabongi, F. J. (2008). The Integration of BIM in the Undergraduate Curriculum: an analysis of undergraduate courses.

Thomas, D. and Miner R (2007 September) BIM Contractual Risks Change with Technology. Construction Executive. 